\title{
Clinical Outcomes of Treatment with Filgrastim Versus a Filgrastim Biosimilar and Febrile Neutropenia-Associated Costs Among Patients with Nonmyeloid Cancer Undergoing Chemotherapy
}

\author{
Lee S. Schwartzberg, MD; Lincy S. Lal, PhD, PharmD; Sanjeev Balu, PhD, MBA, BPharm; \\ Kim Campbell, PharmD, BCOP; Lee Brekke, PhD; Andrew DeLeon, PharmD; Caitlin Elliott, MS; \\ and Stephanie Korrer, MPH
}

\begin{abstract}
BACKGROUND: Granulocyte colony-stimulating factors such as filgrastim are used to decrease the incidence of febrile neutropenia (FN) among patients with nonmyeloid cancers undergoing chemotherapy treatment. Although the biosimilar filgrastim-sndz has been approved in the United States since 2015, limited real-world comparisons of filgrastim-sndz versus reference filgrastim (filgrastim-ref) have been conducted.
\end{abstract}

OBJECTIVE: To compare FN incidence and assess overall FN-related health care resource utilization and medical costs among U.S. patients with nonmyeloid cancer who received filgrastim-sndz or filgrastim-ref during their first chemotherapy cycle.

METHODS: This was a retrospective claims analysis of patients with nonmyeloid cancer who were enrolled in commercial or Medicare Advantage insurance plans from March 2015 through June 2016 and received filgrastim-sndz or filgrastim-ref during their first observed chemotherapy cycle. Patients with evidence of hematopoietic stem cell transplantation or pregnancy and those with missing demographic information were excluded. FN was defined on the basis of diagnosis codes for neutropenia and fever (N/F); neutropenia and infection (N/I); and neutropenia, infection, and fever (N/I/F). Cohorts were adjusted for differences in baseline patient characteristics using the inverse probability of treatment weighting (IPTW) method, and equivalence testing was used to compare the proportion of patients who developed FN between weighted cohorts. On the basis of the range of neutropenic fever incidence found in the PIONEER clinical trial, FN incidence was considered equivalent if $90 \%$ Cls for between-cohort differences were within $\pm 6 \%$. Mean FN-related health care resource utilization and total FN-related medical costs were calculated for the overall study population.

RESULTS: A total of 3,542 patients were included in the study (172 filgrastim-sndz; 3,370 filgrastim-ref; mean ages 62.1 years and 64.7 years, respectively). After IPTW, there were 162 patients in the filgrastim-sndz cohort and 3,297 in the filgrastim-ref cohort (mean age 64.5 years for both). FN incidence in the weighted filgrastim-sndz versus filgrastim-ref cohorts, respectively, was $1.4 \%$ versus $0.9 \%$ for $N / F, 2.3 \%$ versus $1.7 \%$ for $N / I$, and $0.0 \%$ versus $0.3 \%$ for $\mathrm{N} / \mathrm{I} / \mathrm{F}$; FN incidence was statistically equivalent between treatment cohorts. Among patients in either treatment cohort who developed FN, the proportion with FN-related inpatient stays during the first chemotherapy cycle ranged from $35.0 \%$ for N/I to $70.0 \%$ for N/I/F. Mean (SD) FN-related total medical costs across all patients who developed FN were $\$ 11,977(\$ 18,383)$ for N/F, $\$ 8,040(\$ 14,809)$ for N/I, and $\$ 21,733$ $(\$ 30,003)$ for N/I/F, in 2015 U.S. dollars. For all 3 definitions of FN, the largest proportions (73.5\%-93.4\%) of medical costs were inpatient related.

CONCLUSIONS: In this real-world study of patients with nonmyeloid cancers undergoing chemotherapy, the incidence of FN was statistically equivalent between individuals treated with filgrastim-sndz versus filgrastim-ref during their first chemotherapy cycle. FN-related health care resource utilization and medical costs among patients who developed FN were substantial.

J Manag Care Spec Pharm. 2018;24(10):976-84

Copyright $\odot 2018$, Academy of Managed Care Pharmacy. All rights reserved.

\section{What is already known about this subject}

Febrile neutropenia (FN), a common side effect of myelosuppressive chemotherapy, is associated with increased morbidity, mortality, and health care costs and can compromise the delivery of optimal chemotherapy regimens by necessitating treatment delays or reductions in chemotherapy dose intensity.

Prophylaxis with granulocyte colony-stimulating factors such as filgrastim can reduce the risk of hospitalization, death, and chemotherapy dose intensity reduction among patients whose chemotherapy regimens are associated with high risk of FN. Previous studies have shown that clinical and safety outcomes among patients treated with the biosimilar filgrastim-sndz are similar to those reported historically for reference filgrastim (filgrastim-ref).

\section{What this study adds}

The incidence of FN among patients with nonmyeloid cancers undergoing chemotherapy was statistically equivalent between those treated with filgrastim-sndz versus filgrastim-ref during their first chemotherapy cycle, based on real-world data.

Among patients who developed FN, hospitalization was common and mean total medical costs ranged from $\$ 8,040$ to $\$ 21,733$, depending on the FN definition used.

$\mathrm{F}$ ebrile neutropenia (FN), a common and potentially lifethreatening side effect of myelosuppressive chemotherapy, ${ }^{1}$ predisposes patients to infection and often requires hospitalization and treatment with broad-spectrum antibiotics. ${ }^{2-4}$ Most common in the first cycle of chemotherapy, ${ }^{4,5} \mathrm{FN}$ is associated with increased morbidity and mortality and carries a heavy economic burden ${ }^{4,6-8}$; moreover, its development can 
compromise the delivery of optimal chemotherapy regimens by necessitating treatment delays or reductions in chemotherapy dose intensity, ${ }^{4,9,10}$

Practice guidelines in the United States and Europe recommend prophylaxis with granulocyte colony-stimulating factors (G-CSFs) for patients whose chemotherapy regimens are associated with high $(\geq 20 \%)$ risk of FN. ${ }^{11-13}$ These biologic drugs promote the growth and differentiation of neutrophils to accelerate neutrophil recovery after chemotherapy. ${ }^{2,14}$ G-CSF prophylaxis may also be considered for patients on chemotherapy regimens with intermediate FN risk (10\%-20\%), depending on the presence of patient-related risk factors such as age, disease stage, comorbidities, and previous history of $\mathrm{FN} .{ }^{13}$

Use of G-CSF among patients with solid tumors or nonmyeloid malignancies has been shown to reduce the risk of hospitalization, death, and chemotherapy dose intensity reduction while improving chemotherapy-related quality of life..$^{15}$ These outcomes are associated with substantial economic benefit: It is estimated that in 2014, G-CSF treatment and prophylaxis of patients with cancer resulted in a total social value of $\$ 8.5$ billion, including $\$ 770$ million due to fewer FN-related hospitalizations, $\$ 2.65$ billion due to fewer FN-related deaths, and $\$ 230$ million due to reduced indirect costs. ${ }^{15}$

The G-CSF filgrastim (Neupogen) has been approved in the United States since 1991 for decreasing the incidence of FN among patients with nonmyeloid malignancies who are undergoing chemotherapy associated with a substantial risk of neutropenic complications. ${ }^{16}$ It is well accepted that prophylaxis with filgrastim (or its pegylated counterpart, pegfilgrastim) effectively decreases both FN risk and the severity of FN episodes. ${ }^{13,17,18}$

Expiration of the filgrastim basic patent paved the way for the development of biosimilars such as filgrastim-sndz (Zarxio), which became available in the United States in 2015 as the first biosimilar approved after passage of the Biologics Price Competition and Innovation Act (BPCIA). ${ }^{19}$ Designed to encourage innovation and promote the introduction of lowercost biosimilars, the BPCIA established an abbreviated approval pathway for biologics shown to be highly similar to or interchangeable with a reference drug already approved by the U.S. Food and Drug Administration. ${ }^{19,20}$ Approval of filgrastim-sndz was based on a comprehensive package of analytical, preclinical, and clinical data, ${ }^{19}$ including results from the PIONEER randomized controlled trial, which demonstrated that there were no clinically meaningful differences in safety or efficacy between the biosimilar and the reference drug (filgrastim-ref) for neutropenia prevention among patients with breast cancer receiving myelosuppressive chemotherapy. ${ }^{21}$

Given that patient characteristics and treatment patterns often differ substantially between clinical practice and clinical trial settings, the current evidence supporting the biosimilarity of filgrastim-sndz and filgrastim-ref would be bolstered by real-world comparative studies. A recent European multicenter prospective observational study (MONITOR-GCSF) demonstrated that clinical and safety outcomes among patients treated with filgrastim-sndz (Zarzio) were similar to historically reported data for filgrastim-ref, ${ }^{22}$ but limited real-world comparisons of filgrastim-sndz versus filgrastim-ref have been conducted in the United States or globally.

To help address this evidence gap, we performed a retrospective observational study to compare FN incidence among filgrastim-sndz-treated versus filgrastim-ref-treated patients undergoing chemotherapy treatment for nonmyeloid malignancies in U.S. clinical practice. FN-related health care resource utilization and costs were also assessed across all study patients to enhance understanding of the real-world impact of this condition.

\section{Methods}

\section{Study Design and Data Source}

This was a retrospective claims analysis conducted during a study period of September 1, 2014, through July 31, 2016, using data from the Optum Research Database (ORD), a proprietary U.S. health insurance database that contains fully de-identified medical and pharmacy claims and enrollment information for commercial and Medicare Advantage health plan members. The ORD is geographically diverse across the United States and covers 60 million lives from 1993 to the present.

Medical claims included diagnosis and procedure codes from the International Classification of Diseases, Ninth and Tenth Revisions, Clinical Modification (ICD-9-CM and ICD10-CM); Current Procedural Terminology (CPT) or Healthcare Common Procedure Coding System (HCPCS) codes; and other information. Outpatient pharmacy claims included National Drug Code (NDC) numbers for dispensed medications, quantity dispensed, dose, and number of days supply.

For individuals aged $\geq 18$ years, data in the ORD are also linked to dates of death (month and year) from the Social Security Administration death master file. Institutional review board approval or waiver of authorization was not required for this study, as no identifiable protected health information was extracted or accessed.

\section{Study Sample}

The study population comprised adult patients (aged $\geq 18$ years) with at least 1 claim for filgrastim-sndz or filgrastim-ref during the patient identification period (March 1, 2015, through June 30, 2016) in the first observed cycle of a chemotherapy treatment regimen; the first cycle was chosen for analysis because it is the time of greatest FN risk. ${ }^{4,5}$ Selected patients were required to have at least 1 claim for chemotherapy in the 30 days before the first qualifying receipt of filgrastim-sndz or filgrastim-ref (first chemotherapy date was the index date), at least 1 claim with a diagnosis code for nonmyeloid malignancy (codes are available 
from the authors upon request) during the study period ([index date minus 180 days] through the end of the follow-up period), and continuous health plan enrollment with medical and pharmacy benefits for 6 months before the index date (baseline period) and at least 1 month after the index date. This time frame was chosen to increase the chance of capturing at least 1 complete chemotherapy cycle for each patient. The end of the follow-up period was defined as the end of continuous enrollment, death, or July 31, 2016, whichever came earliest. At least 1 month of follow-up continuous enrollment was required.

Patients were excluded if they had evidence of radiation or surgery on or within 5 days after the index date, any claim for hematopoietic cell transplantation during the study period, evidence of chemotherapy $>30$ days before the first qualifying receipt of filgrastim-sndz or filgrastim-ref, evidence of pregnancy during the 6-month baseline period, or missing demographic information, or had switched G-CSF drugs during the observed chemotherapy cycle. Cohort assignments (filgrastimsndz or filgrastim-ref) were based on the first qualifying claim for G-CSF.

\section{Chemotherapy Lines of Therapy and Cycle Definitions}

This analysis used the first observed chemotherapy course (line of therapy [LOT] for adjuvant, neoadjuvant, or metastatic therapy) for each patient. The first observed LOT began on the index date and included all HCPCS codes for injectable drugs and NDC numbers observed in the claims, as per First Databank and Facts \& Comparisons. ${ }^{23,24}$ The initial regimen in the LOT comprised all agents filled or infused within the first 6 days. The end of the LOT was identified as the earliest of the following: (a) initiation of a new agent or receipt of radiation or surgery after the first 6 days of the cycle; (b) a gap in therapy of $>60$ days after the run-out date of all agents in the chemotherapy regimen; (c) death; or (d) health plan disenrollment or the end of the study period. The first observed chemotherapy cycle began on the first day of the first observed LOT and continued until the earlier of the next fill/infusion of cancer therapy occurring on or after day 8 of the LOT, or the end of the LOT. Chemotherapy cycles that ended due to censoring (i.e., disenrollment or study end) were considered to be incomplete and excluded from the equivalence testing analysis but were included in the analysis of health care resource utilization and medical costs.

\section{Study Measures}

Baseline Characteristics. Demographic and clinical characteristics assessed during the baseline period included age, sex, geographic region, insurance type, Quan-Charlson comorbidity index score, ${ }^{25}$ number of colony-stimulating factor (CSF) doses, length of the first observed chemotherapy cycle, use of CSF prophylaxis, and certain diagnoses and procedures (any cancer, metastatic cancer in general and specific to bone, infection, radiation, surgery, renal or hepatic dysfunction, and prior use of the first observed CSF agent). As FN rarely occurs within the first 5 days of chemotherapy, use of filgrastim-sndz or filgrastim-ref was categorized as prophylactic if it had been initiated on or before day 5 of a chemotherapy cycle ${ }^{26}$; later uses were categorized as treatment.

Incidence of FN. FN was defined on the basis of claims with a combination of diagnosis codes for neutropenia (ICD-9-CM 288.0 or ICD-10-CM D70*), fever (ICD-9-CM 780.61 or ICD10-CM R50.81), or bacterial or fungal infection (codes are available from the authors upon request) in the first or second position, starting after the last dose of filgrastim-sndz or filgrastim-ref in the first observed chemotherapy cycle or the fifth day after the index date, whichever was earlier to the end of the cycle. Outcomes were assessed using 3 definitions of FN: neutropenia + fever (N/F), neutropenia + infection (N/I; bacterial or fungal), and neutropenia + infection (bacterial or fungal) + fever (N/I/F). Use of these definitions to identify patients with FN from administrative claims data was verified previously. ${ }^{27}$

Health Care Resource Utilization and Medical Costs. Mean FN-related health care resource utilization and FN-related medical costs were calculated for the full study population. Claims with a diagnosis code for fever, bacterial or fungal infection, or neutropenia in the first or second position were defined as FN related. The number of ambulatory, emergency room, and inpatient visits and the length of inpatient stays were captured to reflect health care resource utilization. In order for an inpatient stay to be categorized as FN related, an FN diagnosis code was required to be on the facility claim. Total FN-related medical costs were calculated as combined health plan-paid and patient-paid amounts adjusted to 2015 U.S. dollars using the annual medical care component of the Consumer Price Index and were also subcategorized as ambulatory, inpatient, emergency room, or other medical. ${ }^{28}$ For FN-related inpatient stays, all costs generated during the stay were considered attributable to FN.

\section{Statistical Analysis}

Baseline characteristics, health care resource utilization, and medical costs were analyzed descriptively. Results were presented by treatment cohort; numbers and percentages were provided for dichotomous and polychotomous variables, and means and standard deviations (SDs) were provided for continuous variables. Standardized differences were calculated to compare characteristics between cohorts, with values $<10 \%$ considered to indicate high similarity. ${ }^{29}$ All statistical analyses were performed using SAS software package 9.4 (SAS Institute, Cary, NC).

Creation of Weighted Cohorts. For the equivalence analysis, weighted cohorts were created using inverse probability of treatment weighting (IPTW) to control for possible 


\section{FIGURE 1 Sample Selection and Attrition Flow Diagram}
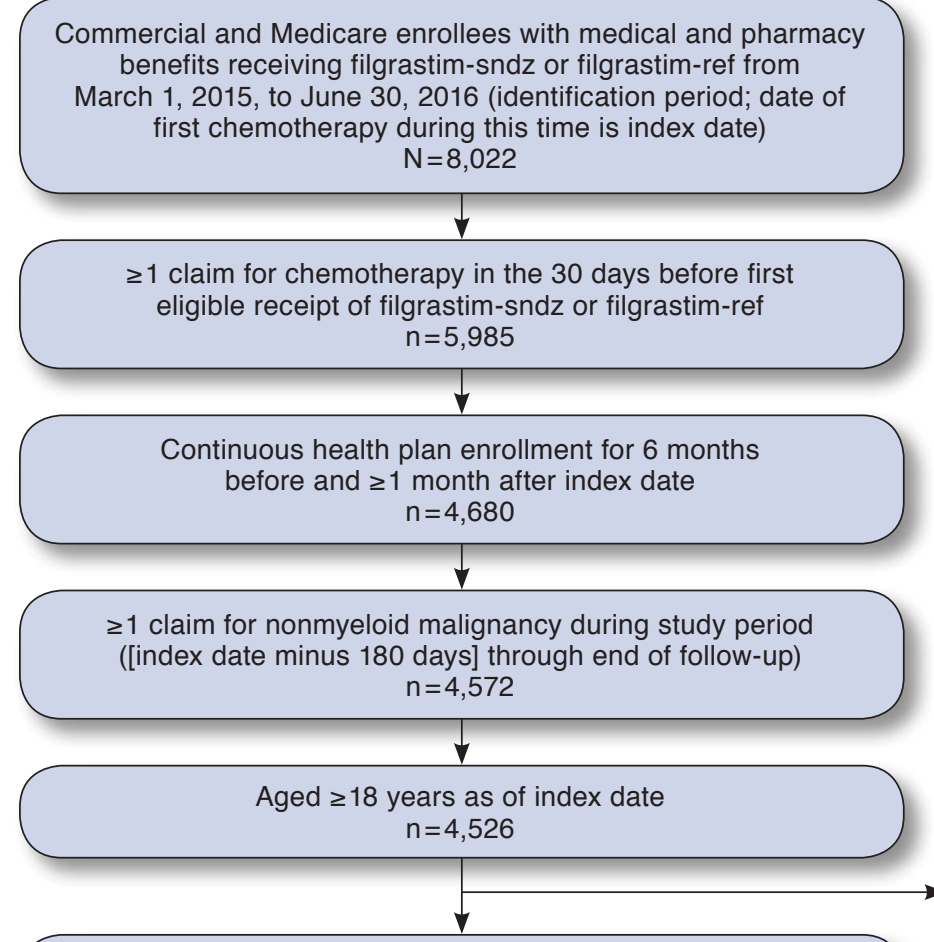

Treated with filgrastim-sndz or filgrastim-ref in chemotherapy cycle 1 without switching during the cycle $n=3,542$

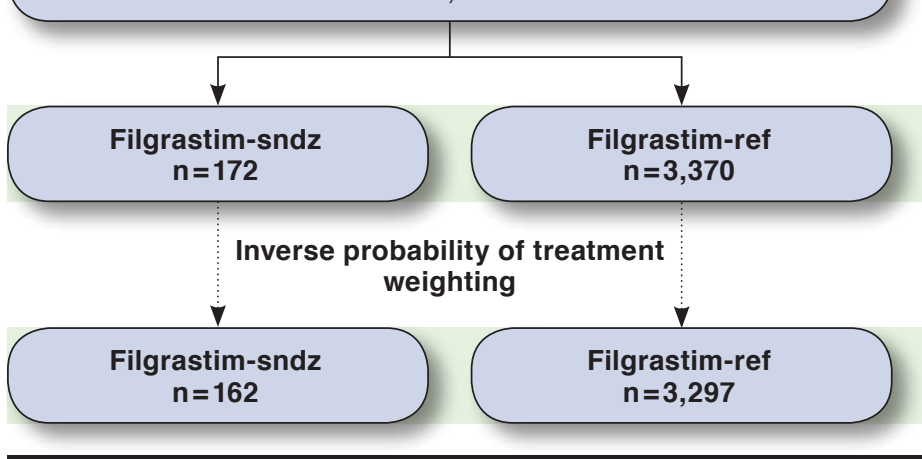

confounding of the relationship between the outcome (development of FN) and the independent variable of interest (G-CSF agent received). ${ }^{29}$ IPTW uses weights based on propensity scores to create a synthetic sample in which the distribution of baseline covariates is independent of treatment assignment; each subject's weight is equal to the inverse probability of receiving the treatment that the subject actually received. The covariates used to calculate propensity scores (selected on the basis of literature review and clinical input) were age, sex, geographic region, insurance type, Quan-Charlson index score, number of CSF doses, length of chemotherapy cycle 1 ,

\section{Exclusions}

- Radiation or surgery on or within 5 days after index date, $\mathrm{n}=436$

- Any claim for hematopoietic cell transplantation during the study period, $n=476$

- Any claim for pregnancy during the 6-month baseline period, $\mathrm{n}=18$

- Missing demographic information, $n=10$

\section{Unweighted cohorts}

use of G-CSF prophylaxis, cancer type, metastatic cancer in general and specific to bone, infection, radiation, surgery, renal or hepatic dysfunction, and prior use of CSF agents. Weighted comparisons were made using the Rao-Scott test for categorical variables and regression with Taylor series variance estimation (i.e., the SAS SURVERREG Procedure) for continuous variables. Statistical Equivalence Testing. FN incidence was calculated among the weighted cohorts for all 3 definitions of FN. Bootstrap methods were used to calculate 90\% confidence intervals (CIs) of the difference in $\mathrm{FN}$ prevalence between 
Clinical Outcomes of Treatment with Filgrastim Versus a Filgrastim Biosimilar and Febrile Neutropenia-Associated Costs Among Patients with Nonmyeloid Cancer Undergoing Chemotherapy

TABLE 1 Baseline Demographic and Clinical Characteristics by Cohort

\begin{tabular}{|c|c|c|c|c|c|c|}
\hline \multirow[b]{2}{*}{ Characteristic } & \multicolumn{3}{|c|}{ Unweighted $^{\mathrm{a}}$} & \multicolumn{3}{|c|}{ Weighted ${ }^{b}$} \\
\hline & $\begin{array}{l}\text { Filgrastim-sndz } \\
\qquad \mathrm{n}=162\end{array}$ & $\begin{array}{l}\text { Filgrastim-ref } \\
\mathbf{n}=3,297\end{array}$ & $\begin{array}{l}\text { Stand. } \\
\text { Diff. (\%) }\end{array}$ & $\begin{array}{c}\text { Filgrastim-sndz } \\
n=162\end{array}$ & $\begin{array}{c}\text { Filgrastim-ref } \\
\mathbf{n}=3,297\end{array}$ & $\begin{array}{l}\text { Stand. } \\
\text { Diff. (\%)d }\end{array}$ \\
\hline Age, years, mean $(\mathrm{SD})^{\mathrm{c}}$ & $62.1(13.4)$ & $64.7(12.9)$ & -19.39 & 64.5 & 64.5 & -0.42 \\
\hline Female, n (\%) & $93(57.4)$ & $2,096(63.6)$ & 12.64 & $109(67.5)$ & $2,087 \quad(63.3)$ & -8.93 \\
\hline \multicolumn{7}{|l|}{ Geographic region, $\mathrm{n}(\%)$} \\
\hline Northeast & $8 \quad(4.9)$ & $483(14.7)$ & -33.12 & $19(11.7)$ & $468 \quad(14.2)$ & -7.50 \\
\hline Midwest & $46(28.4)$ & $902(27.4)$ & 2.31 & $46(28.6)$ & $904(27.4)$ & 2.65 \\
\hline South & $84 \quad(51.9)$ & $1,524(46.2)$ & 11.28 & 79 (49.0) & $1,533(46.5)$ & 5.00 \\
\hline West & $24(14.8)$ & $387(11.7)$ & 9.08 & $17(10.7)$ & $392(11.9)$ & -3.61 \\
\hline Other & $0 \quad(0.0)$ & $1 \quad(0.0)$ & -2.46 & $0 \quad(0.0)$ & $1 \quad(0.0)$ & -2.42 \\
\hline \multicolumn{7}{|l|}{ Insurance type, n (\%) } \\
\hline Commercial & $92(56.8)$ & $1,508 \quad(45.7)$ & 22.25 & $77 \quad(47.6)$ & $1,525(46.3)$ & 2.61 \\
\hline Medicare & $70(43.2)$ & $1,789(54.3)$ & -22.25 & $85(52.4)$ & $1,772 \quad(53.7)$ & -2.61 \\
\hline Quan-Charlson score, mean (SD)c & $5.7 \quad(2.4)$ & $5.8 \quad(2.5)$ & -4.18 & 5.9 & 5.8 & 7.78 \\
\hline Number of CSF doses, mean (SD)c & $2.3 \quad(1.6)$ & $2.1 \quad(1.4)$ & 17.31 & 2.0 & 2.1 & -4.74 \\
\hline Length of cycle 1 , days, mean (SD)c & $21.7 \quad(8.3)$ & $22.2 \quad(9.9)$ & -5.91 & 23.4 & 22.2 & 12.69 \\
\hline Use of CSF prophylaxis, $\mathbf{n}(\%)$ & $61 \quad(37.7)$ & $1,621 \quad(49.2)$ & -23.38 & $75(46.2)$ & $1,603(48.6)$ & -4.77 \\
\hline \multicolumn{7}{|l|}{ Diagnosis/procedures, n (\%) } \\
\hline \multicolumn{7}{|l|}{ Cancer type } \\
\hline Neither & $1 \quad(0.6)$ & $27 \quad(0.8)$ & -2.39 & $1 \quad(0.5)$ & $27 \quad(0.8)$ & -3.43 \\
\hline Lymphoid & $13 \quad(8.0)$ & $181 \quad(5.5)$ & 10.11 & $9 \quad(4.9)$ & $185 \quad(5.6)$ & -3.02 \\
\hline Solid & $141(87.0)$ & $2,775(84.2)$ & 8.18 & $131 \quad(81.1)$ & $2,779 \quad(84.3)$ & -8.49 \\
\hline Both & $7 \quad(4.3)$ & $314 \quad(9.5)$ & -20.61 & $22(13.5)$ & $306 \quad(9.3)$ & 13.15 \\
\hline Metastatic cancer & $64(39.5)$ & $1,552 \quad(47.1)$ & -15.32 & $66(40.7)$ & $1,540 \quad(46.7)$ & -12.22 \\
\hline Metastatic cancer to bone & $17(10.5)$ & $459(13.9)$ & -10.49 & $18(11.2)$ & $454(13.8)$ & -7.89 \\
\hline Infection & $65(40.1)$ & $1,628 \quad(49.4)$ & -18.69 & $90 \quad(55.3)$ & $1,614(49.0)$ & 12.63 \\
\hline Radiation & $14 \quad(8.6)$ & $525(15.9)$ & -22.32 & $32(19.6)$ & $514(15.6)$ & 10.50 \\
\hline Surgery & $59(36.4)$ & $1,248 \quad(37.9)$ & -2.97 & $57(35.2)$ & $1,246 \quad(37.8)$ & -5.37 \\
\hline Renal dysfunction & $41 \quad(25.3)$ & $733(22.2)$ & 7.23 & $36(22.2)$ & $738(22.4)$ & -0.55 \\
\hline Hepatic dysfunction & $40 \quad(24.7)$ & $928 \quad(28.2)$ & -7.84 & $53(32.4)$ & $923(28.0)$ & 9.66 \\
\hline Prior use of CSF agents & $25(15.4)$ & $1,063 \quad(32.2)$ & -40.24 & $48 \quad(29.8)$ & $1,037(31.5)$ & -3.61 \\
\hline \multicolumn{7}{|c|}{$\begin{array}{l}\text { aNumbers include only patients who completed } 1 \text { full chemotherapy cycle, as those with censored data we } \\
\text { bWeighted cohorts are adjusted for covariate imbalance using inverse probability of treatment weighting. } \\
\text { cStandard deviations were not calculated for weighted cohorts. } \\
\text { dBy convention, standardized difference }<10 \% \text { indicates high between-cohort similarity for that variable. } \\
\text { CSF= colony-stimulating factor; SD = standard deviation; stand. diff. = standardized difference. }\end{array}$} \\
\hline
\end{tabular}

groups. On the basis of the range of neutropenic fever incidence reported in the PIONEER trial, ${ }^{21} 90 \%$ CIs within $\pm 6 \%$ were considered to denote statistical equivalence between cohorts. ${ }^{30}$

\section{Results}

\section{Study Sample}

Of the 8,022 commercial and Medicare enrollees with medical and pharmacy benefits who received 1 of the study drugs during the patient identification period, 3,542 met the remaining study criteria and were included in the unweighted treatment cohorts (172 filgrastim-sndz, 3,370 filgrastim-ref; Figure 1). After IPTW, there were 162 patients in the filgrastim-sndz cohort and 3,297 in the filgrastim-ref cohort.
Mean (SD) ages for the unweighted filgrastim-sndz and filgrastim-ref cohorts were 62.1 (13.4) years and 64.7 (12.9) years, respectively (Table 1). Mean age was 64.5 years for both weighted treatment cohorts. The majority of patients were female (ranging from $57.4 \%$ of the unweighted filgrastim-sndz cohort to $67.5 \%$ of the weighted filgrastim-sndz cohort). The mean (SD) numbers of CSF doses received in the unweighted filgrastim-sndz and filgrastim-ref cohorts were 2.3 (1.6) and 2.1 (1.4), respectively (Table 1). Although most baseline demographic and clinical characteristics were similar between cohorts, the unweighted cohorts were statistically different with respect to age; geographic region; insurance type; number of CSF doses; use of CSF prophylaxis and treatment; and the prevalence of several cancer types, infection, radiation, and 


\section{TABLE 2 Incidence of Febrile Neutropenia} by Weighted ${ }^{a}$ Cohort

\begin{tabular}{l|c|c|c}
\hline $\begin{array}{l}\text { Febrile Neutropenia } \\
\text { Definition, } \mathbf{n}(\%)\end{array}$ & $\begin{array}{c}\text { Filgrastim- } \\
\text { snd } \mathbf{z} \\
\mathbf{n}=\mathbf{1 6 2}\end{array}$ & $\begin{array}{c}\text { Filgrastim- } \\
\text { ref } \\
\mathbf{n}=3,297\end{array}$ & $\begin{array}{c}\text { Difference of } \\
\text { Percentages } \\
(90 \% \text { CI) }\end{array}$ \\
\hline Neutropenia+fever & $2(1.4)$ & $30(0.9)$ & $0.47(-0.86-2.87)$ \\
\hline Neutropenia+infection & $4(2.3)$ & $57(1.7)$ & $0.57(-1.57-4.41)$ \\
\hline $\begin{array}{l}\text { Neutropenia } \\
\text { infection + fever }\end{array}$ & $0(0.0)$ & $10(0.3)$ & $-0.3 \mathrm{c}$ \\
\hline
\end{tabular}

aWeighted cohorts are adjusted for covariate imbalance using inverse probability of treatment weighting.

${ }^{b}$ Confidence intervals are based on the bias-adjusted bootstrap method with 10,000 bootstrap replications.

'Confidence interval is not displayed because the incidence of FN in the weighted filgrastim-sndz cohort is 0 .

CI= confidence interval.

prior use of CSF. After IPTW, standardized differences were acceptably low for between-cohort comparisons of all baseline characteristics.

\section{Incidence of FN}

FN incidence between the weighted treatment cohorts was statistically equivalent (90\% CI of difference of percentages within $\pm 6 \%$; Table 2). FN incidence in the filgrastim-sndz versus filgrastim-ref cohorts, respectively, was $1.4 \%(2 / 162)$ versus $0.9 \%$ $(30 / 3,297)$ for N/F (difference [90\% CI] $=0.47$ [-0.86-2.87]); $2.3 \%$ $(4 / 162)$ versus $1.7 \%(57 / 3,297)$ for $\mathrm{N} / \mathrm{I}$ (difference $[90 \% \mathrm{CI}]=$ 0.57 [1.57-4.41]); and $0.0 \%(0 / 162)$ versus $0.3 \%(10 / 3,297)$ for $\mathrm{N} / \mathrm{I} / \mathrm{F}$ (difference $=0.3$; $\mathrm{CI}$ was not calculated for this definition because the incidence of $\mathrm{FN}$ was 0 in the filgrastim-snd $z$ cohort).

\section{FN-Related Health Care Resource Utilization and Medical Costs}

Among patients in either treatment cohort who developed $\mathrm{FN}$, the proportion with FN-related emergency room visits ranged from $30.0 \%$ (18/60) for N/I to $62.5 \%$ (20/32) for N/F, and the proportion with FN-related inpatient stays ranged from $35.0 \%$ (21/60) for N/I to 70.0\% (7/10) for N/I/F (Table 3). Mean (SD) FN-related total medical costs in 2015 U.S. dollars were $\$ 11,977(\$ 18,383)$ for N/F; $\$ 8,040(\$ 14,809)$ for N/I; and $\$ 21,733(\$ 30,003)$ for N/I/F (Table 4). The largest proportion of medical costs for all 3 definitions of FN was inpatient related: $82.5 \%(\$ 9,852 / \$ 11,977)$ for $\mathrm{N} / \mathrm{F}, 73.5 \%(\$ 5,911 / \$ 8,040)$ for N/I, and $93.4 \%(\$ 20,304 / \$ 21,733)$ for N/I/F.

\section{Discussion}

The present analysis is one of the first to confirm the equivalence of filgrastim-sndz with filgrastim-ref by directly comparing FN incidence among real-world patients treated with these drugs. Among patients undergoing chemotherapy for nonmyeloid cancers, the proportion that developed FN

\begin{tabular}{|c|c|c|c|}
\hline Health Care Resources & $\begin{array}{c}\text { Neutropenia }+ \\
\text { Fever } \\
\mathbf{n}=32\end{array}$ & $\begin{array}{c}\text { Neutropenia }+ \\
\text { Infection } \\
\mathbf{n}=60\end{array}$ & $\begin{array}{c}\text { Neutropenia }+ \\
\text { Infection }+ \\
\text { Fever } \\
\mathbf{n}=10\end{array}$ \\
\hline \multicolumn{4}{|l|}{ Ambulatory } \\
\hline $\begin{array}{l}\text { Number of ambulatory } \\
\text { visits, mean (SD) }\end{array}$ & $1.6 \quad(1.7)$ & $3.1 \quad(2.7)$ & $2(2.8)$ \\
\hline $\begin{array}{l}\text { Patients with ambulatory } \\
\text { visits, } \mathrm{n}(\%)\end{array}$ & $21(65.6)$ & $51(85.0)$ & $5(50.0)$ \\
\hline \multicolumn{4}{|l|}{ Emergency room } \\
\hline $\begin{array}{l}\text { Number of emergency } \\
\text { room visits, mean (SD) }\end{array}$ & $0.7 \quad(0.6)$ & $0.3 \quad(0.5)$ & $0.6 \quad(0.5)$ \\
\hline $\begin{array}{l}\text { Patients with emergency } \\
\text { room visits, } \mathrm{n}(\%)\end{array}$ & $20(62.5)$ & $18(30.0)$ & $6(60.0)$ \\
\hline \multicolumn{4}{|l|}{ Inpatient } \\
\hline $\begin{array}{l}\text { Number of inpatient stays, } \\
\text { mean (SD) }\end{array}$ & $0.6 \quad(0.5)$ & $0.4 \quad(0.5)$ & $0.7 \quad(0.5)$ \\
\hline $\begin{array}{l}\text { Patients with inpatient } \\
\text { stays, } \mathrm{n}(\%)\end{array}$ & $18(56.3)$ & $21(35.0)$ & $7(70.0)$ \\
\hline $\begin{array}{l}\text { Length of inpatient stay, }{ }^{a} \\
\text { days, mean (SD) }\end{array}$ & $4.4 \quad(9.1)$ & $2.9 \quad(7.2)$ & $9.0(15.2)$ \\
\hline
\end{tabular}

during their first observed chemotherapy cycle was statistically equivalent between those treated with filgrastim-sndz versus filgrastim-ref. Our findings are congruent with results of the PIONEER randomized controlled trial, which demonstrated that there were no clinically meaningful differences in FN incidence or FN-related hospitalization between patients treated with the biosimilar versus the reference drug. ${ }^{21}$ Moreover, our results expand on those of the MONITOR-GCSF study, which concluded that the safety and efficacy of biosimilar filgrastim prophylaxis in clinical practice were within the ranges previously reported for filgrastim-ref. ${ }^{22}$

This demonstration of real-world equivalence between filgrastim-sndz and filgrastim-ref has important implications for improving access to G-CSF treatment in clinical practice. FN is a costly condition, both economically and in terms of patient morbidity and mortality. It frequently requires hospitalization-indeed, 7 of 10 patients in the present study who met the strictest definition of FN (N/I/F) had an inpatient stay-and patients hospitalized for FN have considerable risk of death as well as large health care expenditures, ${ }^{6-8}$ with the mean cost of a single FN-related inpatient stay surpassing $\$ 22,000$. $^{8}$

In light of these data, it is perhaps unsurprising that G-CSF prophylaxis may be cost saving among patients for whom it is guideline recommended. ${ }^{31}$ However, only about $17 \%$ of such patients actually receive prophylaxis, and a substantial additional proportion receive treatment that is inconsistent with guidelines (e.g., of insufficient duration). ${ }^{1,22,32,33}$ This 


\begin{tabular}{|c|c|c|c|}
\hline TABLE 4 & \multicolumn{3}{|c|}{$\begin{array}{l}\text { Febrile Neutropenia-Related Medical } \\
\text { Costs }{ }^{a} \text { Among Individuals with an } \\
\text { Associated Event }\end{array}$} \\
\hline $\begin{array}{l}\text { Costs, \$ } \\
\text { Mean (SD) }\end{array}$ & $\begin{array}{l}\text { Neutropenia } \\
+ \text { Fever } \\
n=60\end{array}$ & $\begin{array}{c}\text { Neutropenia } \\
+ \text { Infection } \\
n=32\end{array}$ & $\begin{array}{c}\text { Neutropenia }+ \\
\text { Infection + Fever } \\
\mathbf{n}=10\end{array}$ \\
\hline Total medical & $11,977(18,383)$ & $8,040(14,809)$ & $21,733(30,003)$ \\
\hline Ambulatory & $1,084 \quad(1,524)$ & $1,934 \quad(2,420)$ & $896 \quad(1,762)$ \\
\hline Inpatient & $9,852(18,806)$ & $5,911(14,898)$ & $20,304(30,282)$ \\
\hline Emergency room & $560 \quad(1,642)$ & (145) & $141 \quad(138)$ \\
\hline Other medical & $480 \quad(1,870)$ & (443) & (988) \\
\hline
\end{tabular}

phenomenon was also observed in our study, as patients in both treatment cohorts received approximately 2 G-CSF doses only, on average. The consequences of this widespread G-CSF underutilization are clear: In a recent retrospective claims analysis of patients whose chemotherapy regimens and other characteristics warranted CSF prophylaxis, half of all FN episodes occurred among those who had received either no prophylaxis or prophylaxis that was guideline noncompliant and associated with poorer clinical outcomes. ${ }^{1,32,34}$

It is thus apparent that increased use of G-CSF has the potential to reduce $\mathrm{FN}$ incidence among patients receiving chemotherapy. However, G-CSFs, like many biologics, are expensive drugs, and evidence suggests that cost is a barrier to treatment access for some patients..$^{33,35}$ Given that filgrastimsndz is less costly than filgrastim-ref-15\% less expensive at the time of its 2015 U.S. launch ${ }^{36}$-increasing use of the biosimilar has the potential to promote guideline compliance by improving drug access. This scenario has already been borne out in Europe, where burgeoning acceptance of biosimilar filgrastim since its 2008 approval has led to more widespread use of prophylaxis, suggesting that health care providers are more able and/or willing to follow clinical guidelines now that the biosimilar is available. ${ }^{37}$

Notably, European studies demonstrating that biosimilar filgrastim is the most cost-efficient approach for preventing FN among patients undergoing myelosuppressive chemotherapy are being replicated in the United States, ${ }^{38,39}$ with recent analyses concluding that prophylaxis with filgrastim-sndz is costefficient in routine clinical practice relative to both filgrastim-ref and pegfilgrastim, ${ }^{40}$ and that widespread use of the biosimilar in place of filgrastim-ref would yield cost savings sufficient to treat thousands of additional patients on a budget-neutral basis. ${ }^{41}$

In the present study, the prevalence of FN ranged from $0.0 \%$ to $2.3 \%$ in the filgrastim-sndz group and from $0.3 \%$ to $1.7 \%$ in the filgrastim-ref group (depending on the FN definition used) and the overall rate of FN-related hospitalization ranged from $0.28 \%$ to $0.59 \%$ (depending on FN definition). These findings suggest a rate of $\mathrm{FN}$ that is lower than the 1.3\%-3.5\% observed in previous administrative claims analyses assessing the incidence of neutropenic complications (defined as hospitalizations with a neutropenia diagnosis code) among filgrastim-treated cancer patients undergoing chemotherapy., 18,26,42,43

This discrepancy is likely due in part to the fact that earlier analyses included data prior to a 2006 revision of the American Society of Clinical Oncology guidelines, which changed the FN risk cutoff for prophylaxis from $40 \%$ to $20 \% .{ }^{44}$ In addition, previous analyses identified FN based on the presence of a diagnosis code for neutropenia, whereas our more restrictive definition required at least the presence of codes for neutropenia plus fever or infection. As the stricter definition (which is also used in clinical trials) has been shown to have higher positive predictive value and sensitivity, ${ }^{21,27}$ our study may provide a more accurate reflection of FN incidence among chemotherapy-treated patients in real-world clinical practice.

Our results also underscore the substantial economic burden of FN among patients undergoing chemotherapy. Mean FN-related inpatient costs for the most stringent definition of FN were $\$ 21,733$, aligning closely with the $\$ 18,880$ - $\$ 22,086$ range indicated by earlier analyses with similar study populations. ${ }^{6-8}$ In accordance with existing evidence that hospitalization is a major driver of expense in this patient population, ${ }^{8}$ $73.5 \%-93.4 \%$ of total FN-related medical costs in the present study were associated with inpatient stays.

\section{Limitations}

Our findings should be interpreted in light of certain limitations. Because this study was conducted in a managed care population among patients who met the study criteria, its results may not be generalizable to other populations (e.g., uninsured patients, those on fee-for-service plans, or other populations similar to those excluded from the analysis). In addition, the number of eligible patients with a claim for filgrastim-sndz during the identification period was low, as the study was conducted within the first 2 years of the drug's U.S. approval. The effect of small sample size on the equivalence analysis was mitigated by adjusting for covariates using a weighting method (IPTW using propensity scores) rather than a matching method, which allowed us to retain as many patients as possible in the final study cohort. However, the limited sample size precluded meaningful comparison of FN-related health care resource utilization and costs for filgrastim-sndz versus filgrastim-ref.

Finally, because causality was not examined in this analysis, differences in study outcomes cannot be definitively attributed to the G-CSF agent received. Moreover, it is possible that the minimal exposure of patients to either G-CSF during the study period (due to the low mean number of doses received) may have masked any potential differences in efficacy. 
This study is also subject to limitations inherent to administrative claims analyses. Administrative claims data are collected for the purpose of billing, not research; therefore, the presence of a diagnosis code on a medical claim does not prove the presence of disease, as diagnoses may be coded incorrectly or included as rule-out criteria. Although the diagnosis codes used to identify patients with FN in this study were chosen on the basis of literature review and applied within a limited time frame after chemotherapy administration, any coding errors or inconsistencies could lead to misidentification of patients with the outcome of interest.

It should be noted, however, that such errors were expected to be infrequent because proper claims documentation is a prerequisite for optimal reimbursement for provided health care services. Moreover, we did not foresee any systematic differences in the occurrence of errors between treatment cohorts in this study, or between our study and those in the existing literature.

\section{Conclusions}

In this real-world study of patients with nonmyeloid cancers undergoing chemotherapy, the incidence of FN was statistically equivalent between individuals treated with filgrastim-sndz versus filgrastim-ref during their first chemotherapy cycle. Availability of biosimilar filgrastim as a treatment option has the potential to improve patient access to G-CSF treatment and promote physician compliance with prophylaxis guidelines.

\section{Authors}

LEE S. SCHWARTZBERG, MD, Vector Oncology and The West Clinic, Memphis, Tennessee. LINCY S. LAL, PhD, PharmD; LEE BREKKE, PhD; CAITLIN ELLIOTT, MS; and STEPHANIE KORRER, MPH, Optum, Eden Prairie, Minnesota. SANJEEV BALU, PhD, MBA, BPharm; ANDREW DELEON, PharmD; and KIM CAMPBELL, PharmD, BCOP, Sandoz, Princeton, New Jersey.

AUTHOR CORRESPONDENCE: Lincy Lal, PhD, PharmD, Optum, 11000 Optum Cir., Eden Prairie, MN 55344.

Tel.: 281.437.1963; E-mail: lincy.lal@optum.com.

\section{ACKNOWLEDGMENTS}

Medical writing services were provided by Yvette Edmonds, $\mathrm{PhD}$, an employee of Optum. The authors also thank Sarah Peirce-Sandner, MSc, for assistance with the literature review.

\section{REFERENCES}

1. Weycker D, Barron R, Edelsberg J, Kartashov A, Legg J, Glass AG. Risk and consequences of chemotherapy-induced neutropenic complications in patients receiving daily filgrastim: the importance of duration of prophylaxis. BMC Health Serv Res. 2014;14:189.

2. Bennett CL, Djulbegovic B, Norris LB, Armitage JO. Colony-stimulating factors for febrile neutropenia during cancer therapy. N Engl J Med. 2013;368(12):1131-39.

3. National Comprehensive Cancer Network. Clinical practice guidelines in oncology (NCCN Guidelines). Prevention and treatment of cancer-related infections. 2017. Available at: https://www.nccn.org/professionals/physician_gls/f_guidelines.asp. Accessed April 9, 2018.

4. Culakova E, Thota R, Poniewierski MS, et al. Patterns of chemotherapyassociated toxicity and supportive care in U.S. oncology practice: a nationwide prospective cohort study. Cancer Med. 2014;3(2):434-44.

5. Crawford J, Dale DC, Kuderer NM, et al. Risk and timing of neutropenic events in adult cancer patients receiving chemotherapy: the results of a prospective nationwide study of oncology practice. J Natl Compr Canc Netw. 2008;6(2):109-18

6. Kuderer NM, Dale DC, Crawford J, Cosler LE, Lyman GH. Mortality, morbidity, and cost associated with febrile neutropenia in adult cancer patients. Cancer. 2006;106(10):2258-66.

7. Dulisse B, Li X, Gayle JA, et al. A retrospective study of the clinical and economic burden during hospitalizations among cancer patients with febrile neutropenia. J Med Econ. 2013;16(6):720-35.

8. Michels SL, Barron RL, Reynolds MW, Smoyer Tomic K, Yu J, Lyman GH. Costs associated with febrile neutropenia in the U.S. Pharmacoeconomics. 2012;30(9):809-23.

9. Lyman GH, Dale DC, Crawford J. Incidence and predictors of low doseintensity in adjuvant breast cancer chemotherapy: a nationwide study of community practices. J Clin Oncol. 2003;21(24):4524-31.

10. Shayne M, Crawford J, Dale DC, Culakova E, Lyman GH. Predictors of reduced dose intensity in patients with early-stage breast cancer receiving adjuvant chemotherapy. Breast Cancer Res Treat. 2006;100(3):255-62.

11. National Comprehensive Cancer Network. Clinical practice guidelines in oncology (NCCN Guidelines). Myeloid growth factors. 2017. Available at: https://www.nccn.org/professionals/physician_gls/f_guidelines.asp. Accessed April 9, 2018

12. Smith TJ, Bohlke K, Lyman GH, et al. Recommendations for the use of WBC growth factors: American Society of Clinical Oncology Clinical Practice Guideline update. J Clin Oncol. 2015;33(28):3199-212.

13. Aapro MS, Bohlius J, Cameron DA, et al. 2010 update of EORTC guidelines for the use of granulocyte-colony stimulating factor to reduce the incidence of chemotherapy-induced febrile neutropenia in adult patients with lymphoproliferative disorders and solid tumours. Eur J Cancer. 2011;47(1):8-32.

14. Shimazaki C, Oku N, Uchiyama H, et al. Effect of granulocyte colonystimulating factor on hematopoietic recovery after peripheral blood progenitor cell transplantation. Bone Marrow Transplant. 1994;13(3):271-75.

15. Vanderpuye-Orgle J, Sexton Ward A, Huber C, Kamson C, Jena AB. Estimating the social value of G-CSF therapies in the United States. Am J Manag Care. 2016;22(10):e343-49.

16. Neupogen (filgrastim) injection, for subcutaneous or intravenous use. Amgen. Revised 2016. Available at: http://pi.amgen.com/ /media/amgen/ repositorysites/pi-amgen-com/neupogen/neupogen_pi_hcp_english.ashx Accessed April 9, 2018. 
17. Morrison VA, Wong M, Hershman D, Campos LT, Ding B, Malin J. Observational study of the prevalence of febrile neutropenia in patients who received filgrastim or pegfilgrastim associated with 3-4 week chemotherapy regimens in community oncology practices. J Manag Care Pharm. 2007;13(4):337-48. Available at: https://www.jmcp.org/doi/10.18553/ jmcp.2007.13.4.337.

18. Tan H, Tomic K, Hurley D, Daniel G, Barron R, Malin J. Comparative effectiveness of colony-stimulating factors for febrile neutropenia: a retrospective study. Curr Med Res Opin. 2011;27(1):79-86.

19. Raedler LA. Zarxio (Filgrastim-sndz): first biosimilar approved in the United States. Am Health Drug Benefits. 2016;9(Spec Feature):150-54.

20. U.S. Food and Drug Administration. Implementation of the Biologics Price Competition and Innovation Act of 2009. 2016. Available at: https:// www.fda.gov/Drugs/GuidanceComplianceRegulatoryInformation/ ucm215089.htm. Accessed April 9, 2018.

21. Blackwell K, Semiglazov V, Krasnozhon D, et al. Comparison of EP2006, a filgrastim biosimilar, to the reference: a phase III, randomized, doubleblind clinical study in the prevention of severe neutropenia in patients with breast cancer receiving myelosuppressive chemotherapy. Ann Oncol. 2015;26(9):1948-53.

22. Gascon P, Aapro M, Ludwig H, et al. Treatment patterns and outcomes in the prophylaxis of chemotherapy-induced (febrile) neutropenia with biosimilar filgrastim (the MONITOR-GCSF study). Support Care Cancer. 2016;24(2):911-25.

23. FDB MedKnowledge [database online]. South San Francisco, CA: First Databank; 2016. Available at: http://www.fdbhealth.com/fdb-medknowledge/. Accessed April 9, 2018.

24. Drug Facts and Comparisons. Facts \& Comparisons [database online]. St. Louis, MO: Wolters Kluwer Health; 2016.

25. Quan H, Li B, Couris CM, et al. Updating and validating the Charlson comorbidity index and score for risk adjustment in hospital discharge abstracts using data from 6 countries. Am J Epidemiol. 2011;173(6):676-82.

26. Naeim A, Henk HJ, Becker L, et al. Pegfilgrastim prophylaxis is associated with a lower risk of hospitalization of cancer patients than filgrastim prophylaxis: a retrospective United States claims analysis of granulocyte colony-stimulating factors (G-CSF). BMC Cancer. 2013;13:11.

27. Weycker D, Sofrygin O, Seefeld K, Deeter RG, Legg J, Edelsberg J Technical evaluation of methods for identifying chemotherapy-induced febrile neutropenia in healthcare claims databases. BMC Health Serv Res. 2013;13:60

28. U.S. Department of Labor, Bureau of Labor Statistics. Consumer Price Index. Medical Care. Series ID: SUUR0000SAM. 2012. Available at: https:// data.bls.gov/cgi-bin/surveymost. Accessed April 9, 2018.

29. Austin PC. An introduction to propensity score methods for reducing the effects of confounding in observational studies. Multivariate Behav Res. 2011;46(3):399-424.

30. Walker E, Nowacki AS. Understanding equivalence and noninferiority testing. J Gen Intern Med. 2011;26(2):192-96.
31. Dinan MA, Hirsch BR, Lyman GH. Management of chemotherapyinduced neutropenia: measuring quality, cost, and value. J Natl Compr Canc Netw. 2015;13(1):el-7.

32. Weycker D, Li X, Tzivelekis S, et al. Burden of chemotherapy-induced febrile neutropenia hospitalizations in U.S. clinical practice, by use and patterns of prophylaxis with colony-stimulating factor. Support Care Cancer. 2017;25(2):439-47.

33. Potosky AL, Malin JL, Kim B, et al. Use of colony-stimulating factors with chemotherapy: opportunities for cost savings and improved outcomes. J Natl Cancer Inst. 2011;103(12):979-82.

34. Weycker D, Hackett J, Edelsberg JS, Oster G, Glass AG. Are shorter courses of filgrastim prophylaxis associated with increased risk of hospitalization? Ann Pharmacother. 2006;40(3):402-07.

35. Mulcahy AW, Predmore Z, Mattke S. The cost savings potential of biosimilar drugs in the United States. 2014. Available at: https://www.rand. org/content/dam/rand/pubs/perspectives/PE100/PE127/RAND_PE127.pdf. Accessed April 9, 2018.

36. Stanton D. Biosimilars land in the U.S. as Sandoz launches Zarxio. 2015. Available at: http://www.biopharma-reporter.com/Markets-Regulations/ Biosimilars-land-in-the-US-as-Sandoz-launches-Zarxio. Accessed April 9, 2018.

37. Gascon P, Tesch H, Verpoort K, et al. Clinical experience with Zarzio in Europe: what have we learned? Support Care Cancer. 2013;21(10):2925-32.

38. Sun D, Andayani TM, Altyar A, MacDonald K, Abraham I. Potential cost savings from chemotherapy-induced febrile neutropenia with biosimilar filgrastim and expanded access to targeted antineoplastic treatment across the European Union G5 countries: a simulation study. Clin Ther. 2015;37(4):842-57.

39. Aapro M, Cornes P, Abraham I. Comparative cost-efficiency across the European G5 countries of various regimens of filgrastim, biosimilar filgrastim, and pegfilgrastim to reduce the incidence of chemotherapy-induced febrile neutropenia. J Oncol Pharm Pract. 2012;18(2):171-79.

40. McBride A, Campbell K, Bikkina M, MacDonald K, Abraham I, Balu S. Cost-efficiency analyses for the U.S. of biosimilar filgrastim-sndz, reference filgrastim, pegfilgrastim, and pegfilgrastim with on-body injector in the prophylaxis of chemotherapy-induced (febrile) neutropenia. J Med Econ. 2017;20(10):1083-93.

41. McBride A, Balu S, Campbell K, Bikkina M, MacDonald K, Abraham I. Expanded access to cancer treatments from conversion to neutropenia prophylaxis with biosimilar filgrastim-sndz. Future Oncol. 2017;13(25):2285-95.

42. Weycker D, Malin J, Kim J, et al. Risk of hospitalization for neutropenic complications of chemotherapy in patients with primary solid tumors receiving pegfilgrastim or filgrastim prophylaxis: a retrospective cohort study. Clin Ther. 2009;31(5):1069-81.

43. Weycker D, Malin J, Barron R, Edelsberg J, Kartashov A, Oster G. Comparative effectiveness of filgrastim, pegfilgrastim, and sargramostim as prophylaxis against hospitalization for neutropenic complications in patients with cancer receiving chemotherapy. Am J Clin Oncol. 2012;35(3):267-74.

44. Smith TJ, Khatcheressian J, Lyman GH, et al. 2006 update of recommendations for the use of white blood cell growth factors: an evidence-based clinical practice guideline. J Clin Oncol. 2006;24(19):3187-205. 